\title{
Application and comparison of winter wheat canopy resistance estimation models based on the scaling-up of leaf stomatal conductance
}

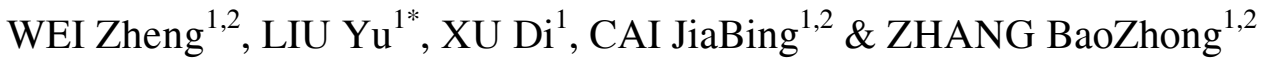 \\ ${ }^{1}$ State Key Laboratory of Simulation and Regulation of Water Cycle in River Basin, China Institute of Water Resources and Hydropower \\ Research, Beijing 100038, China; \\ ${ }^{2}$ National Center of Efficient Irrigation Engineering and Technology Research-Beijing, Beijing 100048, China
}

Received November 19, 2012; accepted March 28, 2013

\begin{abstract}
Canopy resistance estimation model based on the scaling-up leaf stomatal resistance is the focus of evapotrantion research, as there is a need to select the proper scaling-up model for winter wheat in typical areas of North China. Two years of field experimental data are used for the Leuning-Ball and Jarvis stomatal model calibration and validation, canopy resistance estimation models are established based on Leuning-Ball and Jarvis stomatal models, their application effects are compared and verified. Results show that daily variation of stomatal resistance of winter wheat is higher than that of canopy resistance, and there exists scale differences between leaf and canopy scale; Leuning-Ball stomatal model can be better explicated by the response of stomatal conductance towards environmental factors; Leuning-Ball canopy resistance estimation models turn out to be an effective canopy resistance simulation, and thus can be applied to research on the scaling-up of vapor transmission resistance of winter wheat in typical areas of North China.
\end{abstract}

model, radiation, stomatal conductance, canopy resistance, scaling-up, winter wheat

Citation: Wei Z, Liu Y, Xu D, et al. Application and comparison of winter wheat canopy resistance estimation models based on the scaling-up of leaf stomatal conductance. Chin Sci Bull, 2013, 58: 2909-2916, doi: 10.1007/s11434-013-5858-3

Evapotranspiration is an important component of mass and energy exchanges between plant and environment. Therefore, an accurate estimation of evapotranspiration for understanding of which water-carbon and mass \& energy exchanges has vital significance. Models for evapotranspiration include single-layered [1], dual-layered [2] and other multi-layered [3], all of which can be used to describe soil evaporation and plant transpiration through different resistances. Canopy resistance $\left(r_{\mathrm{c}}\right)$ has already been used to calculate crop evapotranspiration, and there are no recommended value [4] of $r_{\mathrm{c}}$ for different crops at different growth stages. Since the availability of $r_{\mathrm{c}}$ in different environments determines the accuracy of evapotranspiration, reliable $r_{\mathrm{c}}$ estimation has turned out to be an important research topic,

*Corresponding author (email: liuyu@iwhr.com) among which $r_{\mathrm{c}}$ estimation models based on the scaling-up leaf stomatal conductance is the research focus.

In the research of scaling-up leaf stomatal resistance to canopy resistance, firstly, canopy resistance is calculated based on direct measured data of leaf stomatal conductance with promoter, photosynthesis system, and other equipment. The analyses and statistics of methods are namely integral average, stratified sampling of top sunshine, weighting, effective leaf area index, level canopy stratification, multi-canopy leaf angle classification, and so on $[5,6]$. Secondly, nonlinear models are used to upscale resistance from leaf to canopy scale. Some methods regard the scaling-up models as functions of different meteorological phenomena, soil and crop growth characteristics [7-9], such as the application of Jarvis model. Jarvis model is mostly based on short-term observed data to discuss the optimal methods of 
canopy resistance models for leaf temperature, saturation deficit, photosynthetic active photo flux density, responsefunction of leaf water potential, and multi-variable functions [10], and some long-term model availability and feasibility. Other methods derive upscale models from the prospective of balance between environment and energy [12,13], such as derivation of canopy resistance by the Penman-Monteith equation or Gradient Theory through measuring sensible and heat latent fluxes or employing radiation balance and other related variables [14].

Most of current studies concentrate on the realization of the scaling-up of $r_{\mathrm{c}}$ based on Jarvis model and taking into consideration photosynthetically active radiation (PAR) distribution [5,15], sun and shade leaves [5,16,17], leaf area $[18,19]$, and so on, or single scale photosynthesis-evapotranspiration-stomatal conductance coupled model [20-22] based on Leuning-Ball stomatal conductance (stomatal resistance) model. However, studies on the establishment of $r_{\mathrm{c}}$ estimation models based on Leuning-Ball stomatal simulation are fewer. This paper will make a case study of winter wheat in typical areas of North China, calibrate and validate parameters of Leuning-Ball and Jarvis stomatal models, regard PAR as scaling-up transformation factor to establish canopy resistance models, compare and verify the application effects of two scaling-up models, and select proper scaling-up methods from winter wheat leaf to canopy scale in typical areas of North China.

\section{Material and methods}

\subsection{Experimental site}

North China is one of the major grain production areas. The experiments are conducted from October 2007 to October 2009 at the Irrigation Experiment Station of China Institute of Water Resources and Hydropower Research in Daxing, Beijing $\left(39^{\circ} 37^{\prime} \mathrm{N}, 116^{\circ} 26^{\prime} \mathrm{E}\right)$. The experimental area falls within the semi-arid continental monsoon climate, where the annual average temperature is $12.1^{\circ} \mathrm{C}$, the effective accumulated temperature $\left(>10^{\circ} \mathrm{C}\right)$ is $4730^{\circ} \mathrm{C}$, the average frost-free period is 185 days, and the sunshine duration is about $2600 \mathrm{~h}$. In addition, the soil at $0-100 \mathrm{~cm}$ depth is sandy loam, and field capacity and bulk density at 0-100 $\mathrm{cm}$ depth are $30.58 \%$ and $1.58 \mathrm{~g} \mathrm{~cm}^{-3}$, respectively.

\subsection{Measurements}

(i) Field evapotranspiration. An open-path eddy covariance (EC) system (Campbell Scientific Inc., USA) was used to measure the actual evapotranspiration and installed near the south side of central winter farmland with the following computational equation:

$$
\lambda E T=\lambda \rho_{a} \overline{w^{\prime} q^{\prime}},
$$

where, ET is evapotranspiration, $\mathrm{mm} \mathrm{s}^{-1} ; \rho_{\mathrm{a}}$ is the air density, $\mathrm{kg} \mathrm{m}^{-3} ; w^{\prime}$ is the pulsating quantity of vertical wind speed, $\mathrm{m} \mathrm{s}^{-1}$; and $q^{\prime}$ is the pulsating quantity of vapor density, $\mathrm{g} \mathrm{m}^{-3}$;

This study employs eddy covariance (EC) system to observe temperature, humidity, and fluctuation value of threedimensional wind speed and soil heat flux during growing seasons of winter wheat. The installing height of the correlator in the field is $3.1 \mathrm{~m}$, with sampling frequency of $10 \mathrm{~Hz}$, and average time of the statistics $30 \mathrm{~min}$. WPL (WebbPearman-Leuning), the air density fluctuation correction, is employed for real time correction of $\mathrm{CO}_{2}$ flux and latent heat flux, and ultrasonic virtual humidity (influence of humidity) correction for that of sensible heat flux [23]. Based on field observation data of winter wheat, energy closure verification is conducted for eddy covariance (EC) system, with an $80 \%$ showing a good performance of the equipments [24]. In the process of handling measured data by eddy covariance (EC) system, abnormal data are eliminated based on the following principles: (1) precipitation daily observation data; (2) data obviously beyond the definition of physical meaning; (3) data when state of sensor showing abnormal; (4) winter wheat irrigation daily data. Besides, error incurred by energy non-closure can also be eliminated through calculation of the daily correction of latent heat flux by the Bowen ratio [25].

(ii) Leaf stomatal conductance and net photosynthetic rate. Leaf stomatal conductance $\left(g_{\mathrm{s}}\right)$, net photosynthetic rate $\left(P_{\mathrm{n}}\right)$, photosynthetic active radiation $\left(\mathrm{PAR}_{\mathrm{a}}\right)$, and temperature and humidity are measured by Li-6400 photosynthesis equipment (Li-COR, USA) every 5 days on sunny days during growing seasons of winter wheat. A number of 3-4 flag leaves are selected to measure once per $2 \mathrm{~h}$ from 8:00 to 16:00. The data are recorded when fluctuation of data is small. The average respectively as measured results for $g_{\mathrm{s}}, P_{\mathrm{n}}$ and related environmental factors can be obtained.

(iii) Plant height and leaf area index. The leaf length $(L)$, plant height $\left(h_{\mathrm{c}}\right)$ and leaf width $(W)$ of plants from the field are measured by a ruler at 15-day intervals throughout the growing season. The relationship between the product of $L$ and $W$ and the same leaf area, measured by a leaf area meter, is obtained previously. The correction coefficient is 0.78 .

(iv) Extinction coefficient. Photosynthetically active radiation of canopy top and bottom are measured by SunScan canopy analysis system (Dynamax, Inc, USA) continuously every 15 days between 10:00-12:00. Finally, canopy extinction coefficient based on actual LAI can be figured out.

\section{Mathematical models}

Based on the Leuning-Ball model as well as the photosynthetic light-response correction model and photosynthetically active radiation attenuation model, this paper regards PAR as the scaling-up transformation factor, and estimates 
the value of $r_{\mathrm{c}}$ based on the Leuning-Ball stomatal model. Meanwhile, $r_{\mathrm{c}}$ estimation model is established according to the Jarvis stomatal model.

\subsection{Leaf stomatal conductance estimation models}

(i) Leuning-Ball stomatal model. Due to limitations of relative humidity and low $\mathrm{CO}_{2}$ density towards the Ball stomatal conductance model, the Leuning corrected Ball model, and established the Leuning-Ball stomatal model [20]:

$$
g_{\mathrm{s}}=m \frac{P_{\mathrm{n}}}{\left(C_{\mathrm{s}}-\Gamma\right)\left(1+\mathrm{VPD}_{\mathrm{s}} / \mathrm{VPD}_{0}\right)}+g_{\mathrm{s} 0},
$$

where, $g_{\mathrm{s}}$ is stomatal conductance, mol m $\mathrm{m}^{-2} \mathrm{~s}^{-1} ; P_{\mathrm{n}}$ is net photosynthetic rate, $\mu \mathrm{mol} \mathrm{m} \mathrm{m}^{-2} \mathrm{~s}^{-1} \Gamma$ is $\mathrm{CO}_{2}$ compensation point, $\mu \mathrm{mol} \mathrm{mol}{ }^{-1} ; C_{\mathrm{s}}$ is $\mathrm{CO}_{2}$ density of leaf surface, $\mu \mathrm{mol} \mathrm{mol}{ }^{-1}$; $\mathrm{VPD}_{\mathrm{s}}$ is leaf surface vapor pressure difference, $\mathrm{kPa} ; m$ and $\mathrm{VPD}_{0}$ are empirical coefficients; and $g_{\mathrm{s} 0}$ is the value of $g_{\mathrm{s}}$ at $\mathrm{CO}_{2}$ compensation point. Relevant calculation formula can be found in [26].

(ii) Jarvis stomatal model. Jarvis believes that stomatal conductance is the product of comprehensive influence of multiple environmental factors, which can be worked out by adding up the responses of stomatal conductance towards a single environmental factor. Yu et al. [27] reported that the accuracy of double-factor Jarvis model mets the short-term requirement. Therefore, winter wheat leaf stomatal model is established referring to double-factor Jarvis model of Zhang et al. [28]:

$$
g_{\mathrm{s}}=g_{\mathrm{s}}\left(\mathrm{PAR}_{\mathrm{a}}\right) f(\mathrm{VPD})=\frac{\mathrm{PAR}_{\mathrm{a}}}{\mathrm{PAR}_{\mathrm{a}}+\alpha} \exp (-\beta \times \mathrm{VPD}),
$$

where, $\mathrm{PAR}_{\mathrm{a}}$ is captured photosynthetically active radiation on the leaf surface, $\mu \mathrm{mol} \mathrm{m} \mathrm{m}^{-2} \mathrm{~s}^{-1}$; VPD is saturated vapor pressure difference, $\mathrm{kPa}$; and $\alpha$ and $\beta$ are empirical coefficients.

\subsection{Photosynthetic light-response correction model}

Considering that rectangular and non-rectangular hyperbolic photosynthetic light-response model fail to give a better description of photo inhibition phenomena, and photo saturated point given is lower than the measured value, Ye et al. [29] put forward a photosynthetic light-response correction model:

$$
P_{n}=a \times \frac{1-c \times \mathrm{PAR}_{\mathrm{a}}}{1+b \times \mathrm{PAR}_{\mathrm{a}}} \times \mathrm{PAR}_{\mathrm{a}}-R_{\mathrm{d}}
$$

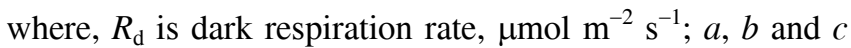
are empirical coefficients; and definition of other variables are the same as above.

\subsection{Photosynthetically available canopy degradation model}

Light attenuation in crop canopy could obey the BeerLambert law, therefore, photosynthetic active radiation captured by leaf $\left(\mathrm{PAR}_{\mathrm{a}}\right)$ can be worked out through the following equation:

$$
\begin{gathered}
\mathrm{PAR}=\mathrm{PAR}_{\mathrm{h}} \exp (-K \xi), \\
\mathrm{PAR}_{\mathrm{a}}=-\mathrm{dPAR} / \mathrm{d} \xi=K \cdot \mathrm{PAR}_{\mathrm{h}} \cdot \exp (-K \xi),
\end{gathered}
$$

where, PAR, and $\mathrm{PAR}_{\mathrm{h}}$ are photosynthetically active radiation at certain canopy height and at the top of canopy respectively, $\mu \mathrm{mol} \mathrm{m} \mathrm{m}^{-2} \mathrm{~s}^{-1}$; $\xi$ is leaf area index from a certain height to the top of canopy; and $K$ is extinction coefficient.

\subsection{Canopy resistance estimation models}

Taking PAR as the scaling-up transformation factor [30], suppose that the underlying surface is uniform distribution and ignoring the influence of soil vaporization, vapor pressure variation inside the canopy and $\mathrm{CO}_{2}$ density variation $[31,32]$. The scaling-up canopy resistance estimation model can be obtained as:

$$
1 / r_{\mathrm{c}}=\int g_{\mathrm{s}} \mathrm{d} \xi=\int_{0}^{\mathrm{LAI}} g_{\mathrm{s}} \mathrm{d} \xi .
$$

By substituting eqs. (2) and (4) into eq. (7), the Leuning-Ball canopy resistance model can be obtained as:

$$
\begin{aligned}
& 1 / r_{\mathrm{c}}=\left(g_{\mathrm{sw}}-R_{\mathrm{d}}\right) \times \mathrm{LAI}+\frac{m \times a \times\left(k \times c \times \mathrm{PAR}_{\mathrm{h}}-1\right)}{K \times b \times\left(C_{\mathrm{s}}-\Gamma\right)\left(1+\mathrm{VPD}_{\mathrm{s}} / \mathrm{VPD}_{0}\right)} \\
& \times \ln \left(1+K \times b \times \mathrm{PAR}_{\mathrm{h}} \times \exp (-K \times \mathrm{LAI}) / 1+K \times b \times \mathrm{PAR}_{\mathrm{h}}\right) .
\end{aligned}
$$

By substituting eqs.(3) and (6) into eq.(7), the Jarvis canopy resistance model can be obtained as:

$$
\begin{aligned}
1 / r_{\mathrm{c}}= & \frac{\exp (-\beta \times \mathrm{VPD})}{K} \\
& \times \ln \left(\frac{K \times \mathrm{PAR}_{\mathrm{h}}+\alpha}{K \times \mathrm{PAR}_{\mathrm{h}} \times \exp (-K \times \mathrm{LAI})+\beta}\right) .
\end{aligned}
$$

\subsection{Canopy resistance}

Canopy resistance $\left(r_{\mathrm{c}}\right)$ can be derived from the PenmanMonteith equation:

$$
\begin{gathered}
r_{\mathrm{c}}=\frac{r_{\mathrm{a}}\left(\Delta\left(R_{\mathrm{n}}-G\right)+\rho_{\mathrm{a}} C_{\mathrm{p}} \operatorname{VPD} / r_{\mathrm{a}}-\lambda E T(\Delta+\gamma)\right)}{\gamma \lambda E T}, \\
r_{\mathrm{a}}=\frac{\ln \left(\frac{z-d}{h_{\mathrm{c}}-d}\right) \ln \left(\frac{z-d}{z_{0}}\right)}{k^{2} u_{\mathrm{z}}},
\end{gathered}
$$


where, $r_{\mathrm{a}}$ is aerodynamic resistance, $\mathrm{s} \mathrm{m}^{-1} ; r_{\mathrm{c}}$ is canopy resistance, $\mathrm{s} \mathrm{m}^{-1} ; R_{\mathrm{n}}$ is net radiation, $\mathrm{W} \mathrm{m}^{-2} ; G$ is soil heat flux, $\mathrm{W} \mathrm{m}{ }^{-2} ; \gamma$ is hygrometer constant, $\mathrm{kPa}^{\circ} \mathrm{C}^{-1} ; \Delta$ is saturated vapor pressure-temperature hyperbola slope, $\mathrm{kPa}^{\circ} \mathrm{C}^{-1} ; C_{\mathrm{p}}$ is air specific heat at constant pressure, $\mathrm{J} \mathrm{kg}^{-1} \mathrm{~K}^{-1} ; k$ is Karman constant, and the valued is $0.41 ; z$ is reference height, and the value is $2 \mathrm{~m} ; u_{\mathrm{z}}$ is wind speed at reference height, $\mathrm{m} \mathrm{s}^{-1}$.

Zero-plane displacement height $(d)$ and roughness length governing momentum transfer $\left(z_{0}\right)$ vary with crop height $\left(h_{\mathrm{c}}\right)$, so expression of their relationship can be obtained as [33]:

$$
\begin{aligned}
d & =0.63 h_{\mathrm{c}} \\
z_{0} & =0.13 h_{\mathrm{c}},
\end{aligned}
$$

where, $h_{\mathrm{c}}$ is canopy height, $\mathrm{m}$; and definition of other variables can be the same as above.

\subsection{Model evaluation index}

Model effect is evaluated through determination coefficient $\left(R^{2}\right)$, root mean square error (RMSE), average absolute error (AAE), average relative error (ARE) and model effective figure $(E F)$. The detailed calculation formula can be found in [34].

\section{Result and discussion}

\subsection{Daily variation difference between leaf stomatal resistance and canopy resistance}

Figure 1 shows the daily variation of winter wheat leaf sto- matal resistance $\left(r_{\mathrm{L}}\right)$ and canopy resistance $\left(r_{\mathrm{c}}\right)$, daily variation of $r_{\mathrm{L}}$ and $r_{\mathrm{c}}$ is relatively consistent during different growth stages and under different meteorological conditions from 2007 to 2008 , and 2008 to 2009 . Winter wheat $r_{\mathrm{L}}$ is higher than $r_{\mathrm{c}}$ during two growing seasons, and the increase amplitude is $0.85 \%-487.46 \%$ and $-24.54 \%-223.26 \%$ respectively. By employing non-parametrical test of Friedman (F) to analyze daily variation difference between $r_{\mathrm{L}}$ and $r_{\mathrm{c}}$ (Figure 1), there are 4 groups on typical days showing significant difference at the level of $a=0.05$. The results show that there are significant scale differences between the vapor transmission resistance of leaf and that of canopy, and $r_{\mathrm{L}}$ cannot replace $r_{\mathrm{c}}$ without scaling-up research.

At 14:00, May 20th, 2008 (Figure 1(b)), $r_{\mathrm{L}}$ is relatively higher, the repeated values measured at that moment are $378.76,458.22$ and $1134.38 \mathrm{~s} \mathrm{~m}^{-1}$ respectively, at the same time, instantaneous wind speed are $0.45,0.43$ and $0.13 \mathrm{~m} \mathrm{~s}^{-1}$ respectively. $\mathrm{Xu}$ et al. [35] concluded that the relationship between stomatal resistance and wind speed is negative. The decrease of wind speed at 14:00 could result in the rise of $r_{\mathrm{L}}$. The value of $r_{\mathrm{c}}$ at that moment is slightly different from values at other moments, and $r_{\mathrm{c}}$ is inverted based on the average time of statistics collected by eddy covariance (EC) system in $30 \mathrm{~min}$ interval. This shows that spatial and time scaling-up from leaf to canopy scale is simultaneous [36].

\subsection{Calibration and validation of leaf stomatal con- ductance model}

(i) Calibration of leaf stomatal model. By employing measured data $(n=990)$ of winter wheat during the growing
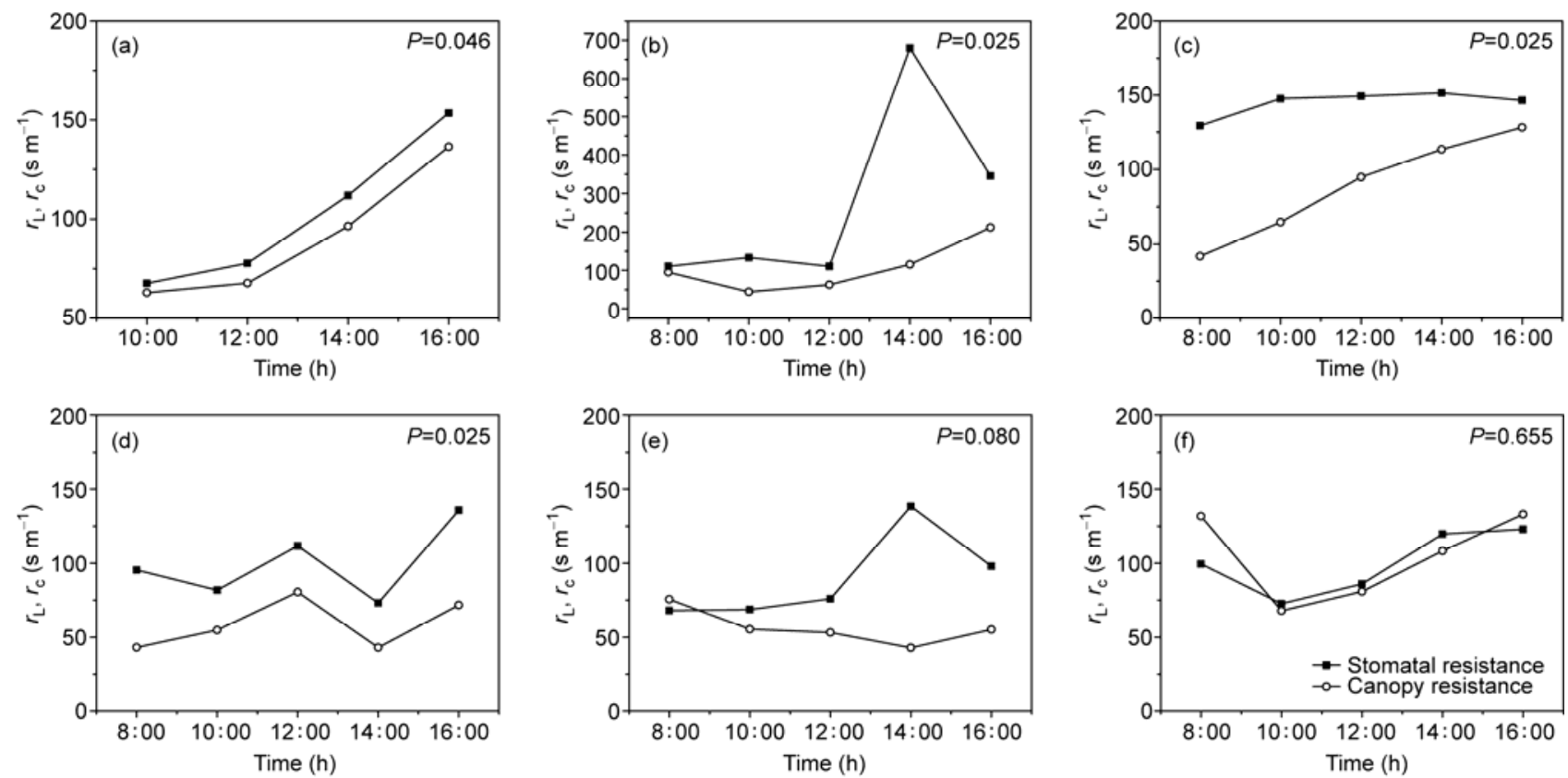

Figure 1 Daily variation of winter wheat leaf stomatal resistance and canopy resistance on typical days for (a) 2008-05-05; (b) 2008-05-20; (c) 2008-06-11; (d) 2009-05-02; (e) 2009-05-08; (f) 2009-05-30. 
season from 2007 to 2008, parameters of leaf stomatal model of Leuning-Ball and Jarvis can be calibrated. That is, in the Leuning-Ball model, $m=15.293, \mathrm{VPD}_{0}=0.657 \mathrm{kPa}$, $g_{\mathrm{s} 0}=0.123$, and in the Jarvis model, $\alpha=265.668$ and $\beta=0.4$. The relationships between measured and simulated values are presented in Figure 2, and the computed goodness of fit indicators is summarized in Table 1 . The regression coefficients between measured and simulated value using LeuningBall and Jarvis stomatal model are respectively 0.95 and 0.93 , with $R^{2} 0.65$ and 0.47 , RMSE 0.08 and $0.09 \mathrm{~mol} \mathrm{~m}^{-2} \mathrm{~s}^{-1}$, AAE 0.06 and $0.07 \mathrm{~mol} \mathrm{~m}^{-2} \mathrm{~s}^{-1}$; and EF 0.71 and 0.61 , respectively. Therefore, Leuning-Ball and Jarvis stomatal model can both effectively simulate the response of winter wheat leaf stomatal conductance towards environmental factors.

(ii) Validation of leaf stomatal model. By employing measured data $(n=1440)$ of winter wheat during the growing season from 2008 to 2009 , the leaf stomatal model of Leuning-Ball and Jarvis can be validated. The relationships between measured and simulated values are presented in Figure 3, and the computed goodness of fit indicators is also summarized in Table 1. The regression coefficients between measured and simulated value by the Leuning-Ball model and Jarvis model are respectively 1.06 and 0.84 , with $R^{2}$ 0.67 and 0.18 , RMSE 0.10 and $0.15 \mathrm{~mol} \mathrm{~m}^{-2} \mathrm{~s}^{-1}$, AAE 0.09 and $0.12 \mathrm{~mol} \mathrm{~m}^{-2} \mathrm{~s}^{-1}$, and $E F 0.55$ and 0.07 , respectively. Compared with the Jarvis model, the Leuning-Ball model can better explain the response variation of winter wheat leaf conductance towards environmental factors. Jarvis doublefactor model cannot reflect the changing characteristics of winter wheat leaf stomatal conductance from 2008 to 2009 , There exist some annual limitations concerning parameters of the Jarvis model, which is consistent with the findings of $\mathrm{Yu}$ et al. [37] that estimation accuracy of the double-variable model meets short-term requirements, while not quite similar to their findings of the 3 to 4 variable model for a long period.

\subsection{Verification of canopy resistance estimation model}

Leuning-Ball and Jarvis canopy resistance estimation model are conducted combined with winter wheat extinction coefficients and leaf area index (Table 2) during different periods, and the established scaling-up models as well as the measured value of winter wheat at typical moments of two growing season. Variations of measured and simulated
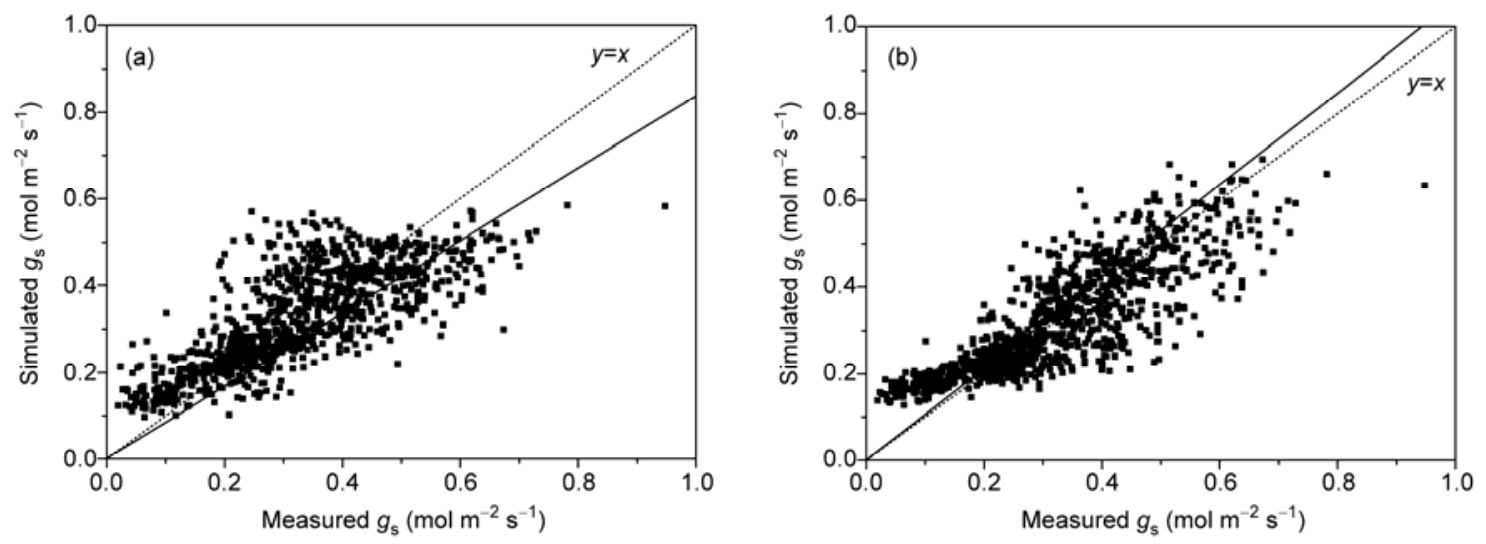

Figure 2 Relationship between measured and simulated leaf stomatal conductance values of 2007-2008 for (a) Jarvis stomatal model; (b) Leuning-Ball stomatal model.
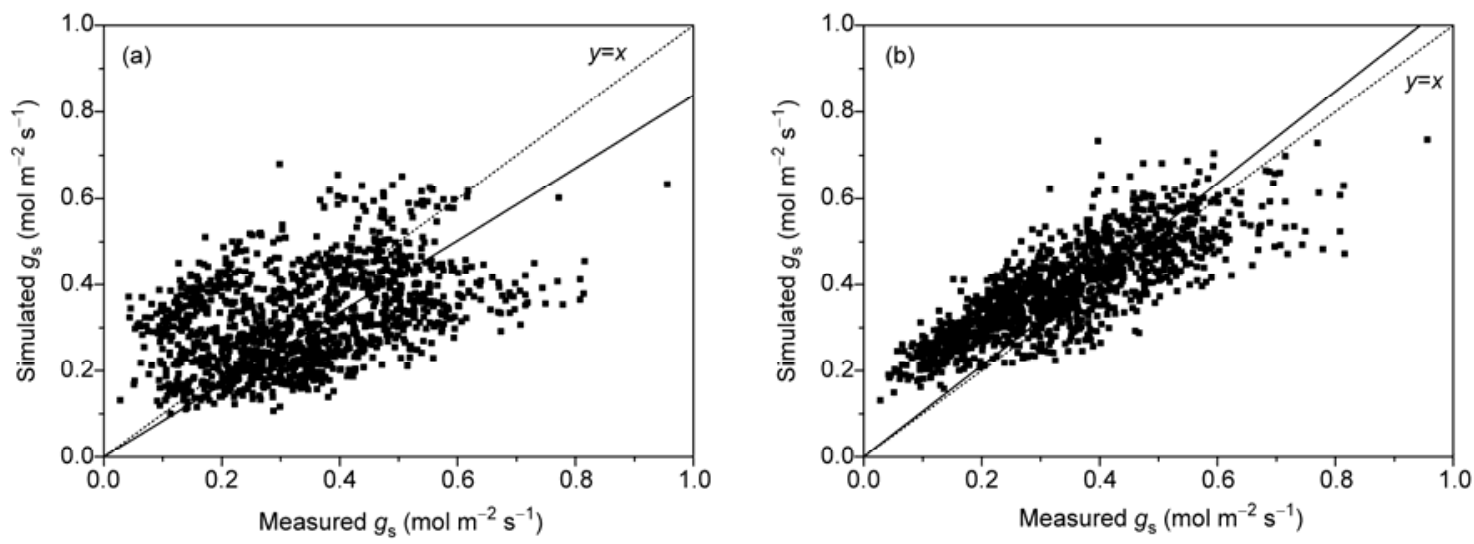

Figure 3 Relationship between measured and simulated leaf stomatal conductance values of 2008-2009 for (a) Jarvis stomatal model; (b) Leuning-Ball stomatal model. 
Table 1 Indicators of goodness of fit relative to model calibration and validation for winter wheat

\begin{tabular}{|c|c|c|c|c|c|c|c|}
\hline & & $b$ & $R^{2}$ & $\operatorname{RMSE}\left(\mathrm{mol} \mathrm{m}^{-2} \mathrm{~s}^{-1}\right)$ & $\operatorname{AAE}\left(\mathrm{mol} \mathrm{m}^{-2} \mathrm{~s}^{-1}\right)$ & $\operatorname{ARE}(\%)$ & $E F$ \\
\hline \multirow{2}{*}{ 2007-2008 } & Leuning-Ball stomatal model & 0.95 & 0.65 & 0.08 & 0.06 & 2.03 & 0.71 \\
\hline & Jarvis stomatal model & 0.93 & 0.47 & 0.09 & 0.07 & 3.46 & 0.61 \\
\hline \multirow{2}{*}{ 2008-2009 } & Leuning-Ball stomatal model & 1.06 & 0.67 & 0.10 & 0.09 & 1.53 & 0.55 \\
\hline & Jarvis stomatal model & 0.84 & 0.18 & 0.15 & 0.12 & 2.69 & 0.07 \\
\hline
\end{tabular}

Table 2 Winter wheat extinction coefficients and leaf area indexes during different periods for winter wheat

\begin{tabular}{ccc}
\hline Date & Extinction coefficient & Leaf area index \\
\hline $2008-05-05$ & 0.69 & 5.01 \\
$2008-05-20$ & 0.83 & 6.21 \\
$2008-06-11$ & 0.78 & 4.83 \\
$2009-05-02$ & 0.56 & 4.68 \\
$2009-05-08$ & 0.69 & 5.73 \\
$2009-05-30$ & 0.58 & 5.12 \\
\hline
\end{tabular}

value of canopy resistance at typical moments are shown in Figure 4, and the computed goodness of fit indicators is summarized in Table 3. The results show that the changing process of measured and simulated value of Leuning-Ball canopy resistance estimation model is generally the same. Regression coefficients between measured and simulated value are respectively, 1.01 and 1.12 , with $R^{2} 0.77$ and 0.46 , RMSE 23.37 and $31.73 \mathrm{~s} \mathrm{~m}^{-1}$, AAE 17.84 and $23.38 \mathrm{~s} \mathrm{~m}^{-1}$, and ARE $19.67 \%$ and $32.10 \%$. This indicates that Leuning-Ball canopy resistance estimation model is relatively suitable to the application of typical areas of North China. However, when measured value of $r_{\mathrm{c}}$ is relatively large, the error will also be increased, showing that Leuning-Ball canopy resistance estimation model and scaling-up transformation factor can only describe canopy vapor transmission resistance, but fail to take the influence of soil water and soil evaporation into consideration. On the contrary, the

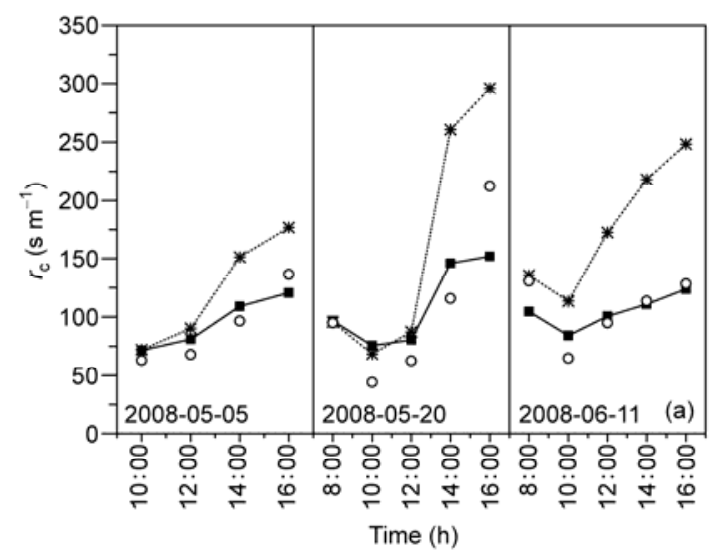

influence of ground surface resistance is included in the process of inversion of $r_{\mathrm{c}}$ by Penman-Monteith equation. Therefore, Leuning-Ball stomatal model should be coupled with soil water factor, and the influence of water stress upon leaf stomatal conductance should be taken into consideration, such as Egea et al. [38] introduces water stress factor $\beta^{\prime}$ into the first item of the right side of eq. (2) to improve net photosynthetic rate-stomatal conductance coupling model.

The measured and simulated values using the Jarvis canopy resistance estimation model are significantly different (Figure 4), the regression coefficient of the simulated and measured values are respectively 0.62 and 1.76 , with $R^{2}$ 0.63 and 0.34, RMSE 67.38 and $97.41 \mathrm{~s} \mathrm{~m}^{-1}$, AAE 49.33 and $64.92 \mathrm{~s} \mathrm{~m}^{-1}$, and ARE $50.69 \%$ and $76.14 \%$. The results show that there are certain difficulties to estimate winter wheat canopy resistance through Jarvis model. This is slighty different from shade and sun leaf models established by Rochette et al. $[5,39,40]$, which can effectively explain canopy conductance. The reason is that shade and sun models can distinguish stomatal conductance of crop shade and sun leaf, photosynthetically active radiation and leaf area index, which can improve the simulation accuracy of canopy conductance (resistance).

\subsection{Sensitivity analyses}

When input items of canopy resistance models of LeuningBall and Jarvis are varied respectively by $\pm 10 \%$, the changed range of ARE of canopy resistance simulated value is

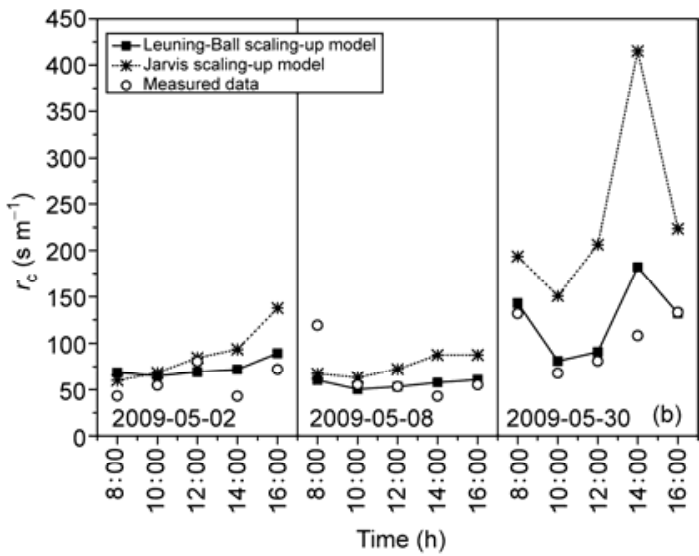

Figure 4 Variation of measured and simulated values of canopy resistance of winter wheat at typical moments for (a) 2007-2008 and (b) 2008-2009. 
Table 3 Indicators of goodness of fit relative to model verification for winter wheat ${ }^{\mathrm{a}}$

\begin{tabular}{|c|c|c|c|c|c|c|c|}
\hline & & Related equation & $R^{2}$ & $\operatorname{RMSE}\left(\mathrm{s} \mathrm{m}^{-1}\right)$ & $\operatorname{AAE}\left(\mathrm{s} \mathrm{m}^{-1}\right)$ & $\operatorname{ARE}(\%)$ & $E F$ \\
\hline \multirow{2}{*}{ 2007-2008 } & $\begin{array}{l}\text { Leuning-Ball canopy resistance esti- } \\
\text { mation model }\end{array}$ & $r_{\mathrm{co}}=1.01 r_{\mathrm{cp}}$ & 0.78 & 23.37 & 17.84 & 19.67 & 0.66 \\
\hline & $\begin{array}{l}\text { Jarvis canopy resistance estimation } \\
\text { model }\end{array}$ & $r_{\mathrm{co}}=0.62 \mathrm{r}_{\mathrm{cp}}$ & 0.63 & 67.38 & 50.69 & 49.33 & 0.42 \\
\hline \multirow{2}{*}{ 2008-2009 } & $\begin{array}{l}\text { Leuning-Ball canopy resistance esti- } \\
\text { mation model }\end{array}$ & $r_{\mathrm{co}}=1.12 r_{\mathrm{cp}}$ & 0.46 & 31.73 & 23.38 & 32.1 & 0.57 \\
\hline & $\begin{array}{l}\text { Jarvis canopy resistance estimation } \\
\text { model }\end{array}$ & $r_{\mathrm{co}}=1.76 r_{\mathrm{cp}}$ & 0.34 & 97.41 & 64.92 & 76.14 & 0.22 \\
\hline
\end{tabular}

(a) $r_{\mathrm{co}}$ stands for canopy resistance inverted by P-M equation; $r_{c}$ stands for canopy resistance based on the scaling-up transformation of leaf stomatal conductance.

Table 4 Analysis of input items and parametric sensitivity of canopy resistance models based on the scaling-up of leaf stomatal conductance

\begin{tabular}{|c|c|c|c|c|c|c|}
\hline & \multirow{2}{*}{ Input items } & \multicolumn{2}{|c|}{ Relative error $(\%)$} & \multirow{2}{*}{$\begin{array}{c}\text { Model } \\
\text { parametric }\end{array}$} & \multicolumn{2}{|c|}{ Relative error (\%) } \\
\hline & & 10 & -10 & & 10 & -10 \\
\hline \multirow{7}{*}{$\begin{array}{l}\text { Leuning-Ball canopy resistance } \\
\text { estimation model }\end{array}$} & $K$ & $-2.16--0.37$ & $0.66-2.57$ & $m$ & $-6.81--2.35$ & $2.46-7.14$ \\
\hline & LAI & $-8.59--5.44$ & $8.03-11.44$ & $\mathrm{VPD}_{0}$ & $-4.66--1.72$ & $1.88-5.40$ \\
\hline & $\mathrm{VPD}_{\mathrm{s}}$ & $-3.07-4.87$ & $-11.26--2.66$ & $\mathrm{~g}_{\mathrm{s} 0}$ & $-9.06--2.62$ & $2.77-8.22$ \\
\hline & $\mathrm{PAR}_{\mathrm{h}}$ & $-9.61--1.70$ & $-3.98-4.09$ & $a$ & $-7.26--3.01$ & $3.20-8.49$ \\
\hline & & & & $c$ & $3.63-7.70$ & $-6.67--3.38$ \\
\hline & & & & $R_{\mathrm{d}}$ & $-1.84-2.35$ & $-2.09-5.16$ \\
\hline & & & & $\Gamma$ & $-8.0--0.65$ & $-5.83-1.43$ \\
\hline \multirow{3}{*}{$\begin{array}{l}\text { Jarvis canopy resistance estimation } \\
\text { model }\end{array}$} & $K$ & $-14.2--0.58$ & $-9.04-5.13$ & $\alpha$ & $2.97-5.11$ & $-4.10--2.97$ \\
\hline & LAI & $-16.51--5.20$ & $-5.98-10.16$ & $\beta$ & $2.67-6.13$ & $-5.84--2.60$ \\
\hline & VPD & $-1.25-14.13$ & $-21.29--2.60$ & & & \\
\hline
\end{tabular}

summarized in Table 4. It is found that the sensitivity of Jarvis model of two input items, namely radiation and leaf area index, is higher than that of Leuning-Ball Model. Therefore, it will be more efficient to improve accuracy of the Jarvis model by distinguishing shade and sun leaves.

When parameters of scaling-up models of Leuning-Ball and Jarvis are varied respectively by $\pm 10 \%$, the changed range of ARE of simulated value of canopy resistance is also summarized in Table 4. It is found that Leuning-Ball stomatal conductance model parameters ( $m$ and $g_{\mathrm{s} 0}$ ), photosynthetic light-response correction model parameter $(a)$, and $\mathrm{CO}_{2}$ compensation point impose greater influence upon Leuning-Ball scaling-up model, and photosynthetic lightresponse correction model parameters ( $c$ and $R_{\mathrm{d}}$ ) follows. When parameters of Leuning-Ball stomatal model $\left(m, \mathrm{VPD}_{0}\right.$ and $g_{\mathrm{s} 0}$ ), and Jarvis stomatal model ( $\alpha$ and $\beta$ ) change between $-10 \%-10 \%$, changed range of ARE of simulated value of canopy resistance is $-9.06 \%-8.22 \%$ and $-5.84 \%-$ $6.13 \%$. Therefore, parameters of Jarvis model $(\alpha$ and $\beta$ ) is less sensitive at a canopy scale.

\section{Conclusions}

Through winter wheat field experiments during two grow- ing seasons, differences of winter wheat vapor transmission resistance of leaf and canopy scale are revealed, and parameters of stomatal conductance models of Leuning-Ball and Jarvis are calibrated and validated. Leuning-Ball and Jarvis canopy resistance estimation model are calculated. Proper methods for winter wheat in typical areas of North China to achieve transformation of the scaling-up of leaf stomatal conductance towards that of canopy resistance are selected by verifying and comparing the application effects of two scaling-up models.

Winter wheat stomatal resistance during two growing seasons is generally higher than that of canopy, with increasing extent being $0.85 \%-487.46 \%$ and $-24.54 \%-223.26 \%$ respectively; there are significant scale difference of vapor transmission resistance of leaf and canopy by employing nonparametric test of Friedman; Leuning-Ball model can better explain winter wheat leaf stomatal conductance compared with Jarvis model; estimation accuracy of long-term stomatal conductance by the Jarvis model is comparatively low; compared with Jarvis canopy resistance estimation model, the Leuning-Ball model can be more effective in estimation of canopy resistance variation by regarding photosynthetic active radiation as the scaling transformation factor; and that parameters of Jarvis canopy resistance estimation model are less sensitive in canopy scale. Therefore, 
the Leuning-Ball canopy resistance estimation model can be applied to scaling-up research of winter wheat vapor transmission resistance in typical areas of North China.

This work was supported by the National Basic Research Program of China (2006CB403405), Recommend International Advanced Agricultural Science and Technology Plan (201009) and the National Natural Science Foundation of China (91125017, 51109225, 51009151 and 50909099).

1 Rana G, Katerji N, Mastrorilli M, et al. Validation of a model of actual evapotranspiration for water stressed soybeans. Agr Forest Meteorol, 1997, 86: 215-224

2 Shuttleworth W J, Wallace J S. Evaporation from sparse crops-An energy combination theory. Q J Royal Meteorol Soc, 1985, 111: 839_ 855

3 Brenner A J, Incoll L D. The effect of clumping and stomatal response on evaporation from sparsely vegetated shrublands. Agr Forest Meteorol, 1997, 84: 187-205

4 Shuttleworth W J. Towards one-step estimation of crop water requirements. T Asabe, 2006, 49: 925-935

5 Irmak S, Mutiibwa D, Irmak A, et al. On the scaling-up leaf stomatal resistance to canopy resistance using photosynthetic photon flux density. Agr Forest Meteorol, 2008, 148: 1034-1044

6 Kato T, Kimura R, Kamichika M. Estimation of evapotranspiration, transpiration ratio and water-use efficiency from a sparse canopy using a compartment model. Agr Water Manage, 2004, 65: 173-191

7 Rana G, Katerji N. Measurement and estimation of actual evapotranspiration in the field under mediterranean climate: A review. Euro J Agron, 2000, 13: 125-153

8 Anadranistakis M, Liakatas A, Kerkides P, et al. Crop water requirements model tested for crops grown in Greece. Agr Water Manage, 2000, 45: 297-316

9 Furon A, Warland J S, Wagner-Riddle C. Analysis of scaling-up resistances from leaf to canopy using numerical simulations. Agron J, 2007, 99: 1483-1491

10 Avissar R, Pielke R A. The impact of plant stomatal control on mesoscale atmospheric circulations. Agr Forest Meteorol, 1991, 54: 353-372

11 Yu G R, Nakayama K, Matsuoka N, et al. A combination model for estimating stomatal conductance of maize (Zea mays L.) leaves over a long term. Agr Forest Meteorol, 1998, 92: 9-28

12 Beven K. A sensitivity analysis of the penman-monteith actual evapotranspiration estimates. J Hydrol, 1979, 44: 169-190

13 Black T A. Estimation of Areal Evapotranspiration. Budapest: IAHS Press, 1989

14 Oltchev A, Ibrom A, Constantin J, et al. Stomatal and surface conductance of a spruce forest: Model simulation and field measurements. Phys Chem Earth, 1998, 23: 453-458

15 Raupach M R. Vegetation-atmosphere interaction and surface conductance at leaf, canopy and regional scales. Agr Forest Meteorol, 1995, 73: 151-179

16 Shen S H, Sun Z B, Chen J M, et al. Modeling of air $\mathrm{CO}_{2}$ concentration and flux in/above a boreal black spruce stand (in Chinese). Acta Meteorol Sin, 2005, 63: 6-17

17 Whitehead D, Okali D, Fasehun F E. Stomatal response to environmental variables in two tropical forest species during the dry season in Nigeria. J Appl Ecol, 1981, 18: 571-587

18 Zhang B Z, Kang S, Li F, et al. Comparison of three evapotranspiration models to bowen ratio-energy balance method for a vineyard in an arid desert region of northwest China. Agr Forest Meteorol, 2008,
148: $1629-1640$

19 Zhou M C, Ishidaira H, Takeuchi K. Estimation of potential evapotranspiration over the yellow river basin: Reference crop evaporation or shuttleworth-wallace? Hydrol Process, 2007, 21: 1860-1874

20 Leuning R. A Critical appraisal of a combined stomatal-photosynthesis model for C3 plants. Plant Cell Environ, 1995, 18: 339-355

21 Yu Q, Wang T D. Photosynthesis effect-evaporation effect-coupling model of stomatal conductance and physical response of $\mathrm{C} 3$ plant leaf towards environmental factors (in Chinese). Bot J, 1998, 40: 740-754

22 Sellers P J, Randall D A, Collatz G J, et al. A revised land surface parameterization $\left(\mathrm{SiB}_{2}\right)$ for atmospheric GCMs. Part I: Model formulation. J Climate, 1996, 9: 676-705

23 Webb E K, Pearman G I, Leuning R. Correction of flux measurements for density effects due to heat and water vapor transfer. Q J Royal Meteorol Soc, 1980, 106: 85-100

24 Liu G S. Study on measurement and calculation methods of crop evapotranspiration quantify (in Chinese). Dissertation of Masteral Degree. Baoding: Heibei Agricultural University, 2008

25 Guo J X, Mei X R, Lu Z G, et al. Eddy-covariance related techniques used to measure field evapotranspiration (in Chinese). China Agri Sci, 2004, 37: 1172-1176

26 Yu G R, Zhuang J, Yu Z L. An attempt to establish a synthetic model of photosynthesis-transpiration based on stomatal behavior for maize and soybean plants grown in field. J Plant Physiol, 2001, 158: 861-874

27 Yu G R, Nakayama K, Lu H Q. Modeling stomatal conductance in maize leaves with environmental variables. J Agr Meteorol, 1996, 52: 321-330

28 Zhang B Z, Liu Y, Xu D, et al. Canopy estimation models based on scaling-up of leaf stomatal conductance of summer maize (in Chinese). Agr Eng J, 2011, 27: 80-86

29 Ye Z P. A new model for relationship between irradiance and the rate of photosynthesis in oryza sativa. Photosynth, 2007, 45: 637-640

30 Meidner H, Mansfield T A. Physiology of Stomata. Maidenhead: McGraw Hill, 1968

31 Warland J S, Furon A C, Wagner-Riddle C. Analysis of scaling-up resistances from leaf to canopy using numerical simulations. Agron J, 2007, 99: 1483-1491

32 Kaufmann M R. Leaf conductance as a function of photosynthetic photon flux density and absolute humidity difference from leaf to air. Plant Physiol, 1982, 69: 1018-1022

33 Yu G R, Sun X M. Continental Ecosystem Flux Observation Principle and Method (in Chinese). Beijing: Higher Education Press, 2006

34 Mccuen R H, Knight Z, Cutter A G. Evaluation of the nash-sutcliffe efficiency index. J Hydrol Eng, 2006, 11: 597-602

$35 \mathrm{Xu} \mathrm{H} \mathrm{F,} \mathrm{Liu} \mathrm{X} \mathrm{T,} \mathrm{Sha} \mathrm{Z,} \mathrm{et} \mathrm{al.} \mathrm{Study} \mathrm{on} \mathrm{the} \mathrm{correlation} \mathrm{between} \mathrm{pro-}$ line, chlorophyll and stoma block under shadings (in Chinese). Agr Sys Sci Compr Res, 2004, 20: 232-234

$36 \mathrm{Xu} \mathrm{D}$. A survey of scaling transformation in irrigation hydrological studies (in Chinese). Irrig J, 2006, 37: 141-149

37 Yu G R, Nakayama K, Matsuoka N, et al. A combination model for estimating stomatal conductance of maize (Zea mays L.) leaves over a long term. Agr Forest Meteorol, 1998, 92: 9-28

38 Egea G, Verhoef A, Vidale P L. Towards an improved and more flexible representation of water stress in coupled photosynthesisstomatal conductance Models. Agr Forest Meteorol, 2011, 151: 1370-1384

39 Zhang B Z, Liu Y, Xu D, et al. Evapotranspiraton estimation based on scaling up from leaf Stomatal conductance to canopy conductance. Agr Forest Meteorol, 2011, 151: 1086-1095

40 Rochette P, Pattey E, Desjardins R L, et al. Estimation of maize (Zea mays L.) canopy conductance by scaling up leaf stomatal conductance. Agr Forest Meteorol, 1991, 54: 241-261

Open Access This article is distributed under the terms of the Creative Commons Attribution License which permits any use, distribution, and reproduction in any medium, provided the original author(s) and source are credited. 